J. Dairy Sci. 95:6185-6185

http://dx.doi.org/10.3168/jds.2011-4942

(C) American Dairy Science Association ${ }^{\circledR}, 2012$.

\title{
Letter to the editor: Underestimation of the net present value of different sexed semen artificial insemination strategies in dairy heifers: A comment on Olynk and Wolf (2007)
}

\section{S. Joezy-Shekalgorabi ${ }^{\star 1}$ and A. A. Shadparvar† \\ *Young Researchers Club, Shahr-e-Qods Branch, Islamic Azad University, Tehran, Iran †Department of Animal Science, Faculty of Agriculture, University of Guilan, Rasht, Iran}

The formulas provided by Olynk and Wolf (2007) for predicting the net present value (NPV) of various sexed semen breeding strategies underestimates this parameter due to the double counting of insemination costs in different services. For the first service, because all heifers are inseminated using sexed or conventional semen, the formulas presented by Olynk and Wolf (2007) are correct. However, for the second to the last service, the insemination costs (IC) change over each service by a coefficient $\left(1-P R_{\text {cum }_{t-1}}\right)$, where $P R_{\text {cum }_{t-1}}$ represents the cumulative percentage pregnant [as defined by Olynk and Wolf (2007)] from the first service to the $t-1$ st service. This coefficient has to be inserted because fewer inseminations would be necessary from the second to last service, which changes the IC of each service.

Olynk and Wolf (2007) obtained the number of service per conception for achieving a minimum cumulative pregnancy rate $\left(\boldsymbol{P} \boldsymbol{R}_{\text {cum }}\right)$ of $90 \%$. The services per conception necessary to achieve this assumption was greater for strategies based on pure or mixed sexed semen AI compared with that based on conventional semen. Thus, it could be concluded that the double counting of insemination costs would have more effect when predicting NPV of sexed semen breeding strategies.

To be more precise, for the conditions described by Olynk and Wolf (2007), we recommend using the following formulas for predicting the NPV over each service:

$$
\begin{gathered}
N P V_{t}=\left(\frac{1}{1+r}\right)^{t / m}\left[\begin{array}{l}
C R_{t} \times V A C \\
-\left(1-P R_{\text {cum }_{t}}\right) \times \text { Feed }-I C
\end{array}\right] \text { for } t=1, \\
N P V_{t}=\left(\frac{1}{1+r}\right)^{t / m}\left\{\begin{array}{l}
\left(1-P R_{\text {cum }_{t-1}}\right) \times \\
{\left[\begin{array}{l}
\left.C R_{t} \times V A C-I C\right] \\
-\left(1-P R_{\text {cum }_{t}}\right) \times \text { Feed }
\end{array}\right.}
\end{array}\right\} \text { for } t=2,3, \ldots, T-1,
\end{gathered}
$$

$$
N P V_{T}=\left(\frac{1}{1+r}\right)^{t / m}\left\{\begin{array}{c}
\left(1-P R_{\text {cum }_{t-1}}\right)\left[C R_{T} \times V A C-I C\right] \\
+\left(1-P R_{\text {cum }_{t}}\right)\left[V C U L L_{T}-\text { Feed }\right]
\end{array}\right\} \text { for } t=T .
$$

where $\mathrm{CR}=$ conception rate, $\mathrm{VAC}=$ value of average calf, Feed $=$ monthly feed and raising costs for nonpregnant, breeding-age heifers, and $\mathrm{VCULL}_{\mathrm{T}}=$ value of culled heifer. Note: definitions of all parameters are the same as those defined by Olynk and Wolf (2007) but are presented here for clarity. However, the first term, $\left(\frac{1}{1+r}\right)^{t / m}$, refers to discount factor, which is related to the discount rate $(r)$ in $t$ th service, $m$ refers to the number of periods per year (Dekkers et al., 2004), and $C R_{t}$ refers to the conception rate of the relevant strategy.

Ignoring the proposed coefficient for IC leads to results similar to those obtained by Olynk and Wolf (2007). On the other hand, considering the coefficient presented above would lead to a higher NPV in the different schemes practiced by Olynk and Wolf (2007). It is expected that implementing the above formula would decrease breakeven heifer calf values and would increase breakeven costs per insemination of sexed semen of the different strategies discussed by Olynk and Wolf (2007). In conclusion, due to underestimation of the NPV resulted from different breeding strategies, we feel that the article by Olynk and Wolf (2007) is biased and it has to be cited considering this error.

\section{REFERENCES}

Dekkers, J. C. M., J. P. Gibson, P. Bijma, and J. C. M. van Arendonk. 2004. Design and Optimization of Animal Breeding Programs. Accessed Mar. 10, 2011. www.une.edu.au/ers/animal-genetics/ Gibson-book.

Olynk, N. J., and C. A. Wolf. 2007. Expected net present value of pure and mixed sexed semen artificial insemination strategies in dairy heifers. J. Dairy Sci. 90:2569-2576.

Received September 16, 2011

Accepted February 12, 2012.

${ }^{1}$ Corresponding author: s_joezy@shahryariau.ac.ir 